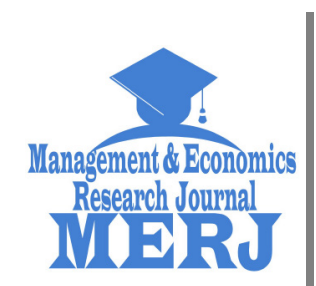

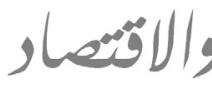

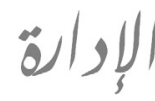

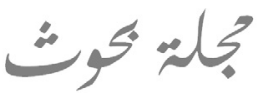

Management \& Economics Research Journal

ISSN 2710-8856 (Online)

ISSN 2676-184X (Print)

Vol. 3 No. 2 (2021), pp. 63-87

https://doi.org/10.48100/merj.2021.162

Check for updates

\title{
Leadership Styles and Firms' Innovation, Mediating Role of Absorptive Capacity: Empirical Evidence from Emerging Economy
}

\author{
Irum Mushtaq ${ }^{1}$ (D), Muhammad Salman Chughtai ${ }^{\bullet}$ (D), Faryal Lashari ${ }^{3}$ (D) \\ ${ }^{1}$ School of Business Administration, Qurtaba University of Science and Information \\ Technology, D.I. Khan Campus (Pakistan) \\ $\checkmark$ irumxubair19@gmail.com \\ ${ }^{2}$ Doctoral Student of Management Sciences, Faculty of Management Sciences, International \\ Islamic University, Islamabad (Pakistan) \\ $\triangle$ salman.phdmgt80@iiu.edu.pk \\ ${ }^{3}$ Doctoral Student of Business Administration, Business School, University of West of \\ Scotland, London Campus (United Kingdom) \\ $\triangle$ b00317654@studentmail.uws.ac.uk
}

Received: 02-03-2021

Accepted: 15-05-2021

Published online: 16-05-2021

\section{How to Cite:}

Mushtaq, I., Chughtai, M. S., \& Lashari, F. (2021). Leadership Styles and Firms' Innovation, Mediating Role of Absorptive Capacity: Empirical Evidence from Emerging Economy. Management \& Economics Research Journal, 3(2), 63-87. https://doi.org/10.48100/merj.2021.162

\begin{abstract}
:
This study contends explicitly that leadership styles (transformational and transactional) are positioned as a pylon for firms' innovation performance. Further, this study contemplates the intermediating inspiration of absorptive capacity (potential and realized) linking leadership
\end{abstract}

- Corresponding author: Faculty of Management Sciences, International Islamic University, Islamabad (Pakistan).

[ $\square$ salman.phdmgt80@iiu.edu.pk]

(C)2021 the Author(s). This is an open-access article distributed under the terms of (CC BY-NC 4.0) which permits use, distribution and reproduction in any medium, provided the original work is properly cited and is not used for commercial purposes. 
Mushtaq, I., Chughtai, M. S., \& Lashari, F.
Leadership Styles and Firms' Innovation, Mediating Role of Absorptive Capacity: Empirical Evidence from

Emerging Economy

styles (transformational and transactional) and firms' innovation. Data was collected from 301 permanent employees working in Pakistani manufacturing firms (food and tobacco) through self-administered questionnaires to test the proposed hypothesis of this study. The study's findings demonstrate a positive influence of leadership styles (transformational and transactional) on the firm's innovative performance. Moreover, both absorptive capacity dimensions (potential and realized) mediate the relationship between leadership styles (transformational and transactional) and innovative performance. This study demonstrates that both leadership styles (transformational and transactional) provide phenomenal path routes to augment firms' innovation. Overall, this study contributed a legitimate illustration of leadership styles strengthening firms' innovation, specifically transactional leadership style, encouraging results within the developing economy perspective.

Keywords: Transformational Leadership, Transactional Leadership, Absorptive Capacity, Potential Absorptive Capacity, Realized Absorptive Capacity, Firm Innovation.

JEL Codes: M00, M1, M5, M10.

\section{Introduction}

Globalization and rapid technological advancement change the business environment, which increases the competition level (Xie et al., 2018) and force organizations to pay attention to innovative performance for survival in the highly competitive globalized economy (Kim \& Koo, 2017; Woods et al., 2018). Organizational innovation can be increased with the support of proper leadership and motivations and by providing a productive environment that further increases the innovative capabilities of the individuals and enables organizations to accomplish competitive advantages (Afsar et al., 2019; Schuckert et al., 2018). In recent years emerging economies have contributed to the globalized economy (Lebedev et al., 2015; Padmanathan et al., 2018).

In the last decades, the phenomenon of leadership has been studied in an industrial and business context (Rehman et al., 2019) because it becomes obligatory for organizations to adopt effective leadership for the accomplishment of their organizational goals and objectives, especially in the environment of high competition (Rehman et al., 2019; Tourish, 2014). Leadership styles are considered a vibrant cradle to foster a firm's innovation (Afsar \& Umrani, 2019; Al-Husseini et al., 2019; Zheng et al., 2016), and effective leadership also plays a meaningful role in the success and failure of firms goals and objectives (Tourish, 2014). Transformational 
leadership (TFL) and transactional leadership (TSL) have been at the vanguard of the leadership literature in recent areas, which not only sufficiently influence organizational management but also provide a better platform of leadership, especially for developing economies (Ohiorhenuan, 2019; Saleem et al., 2019). Leadership not only influence the job satisfaction level of individuals (Rothfelder et al., 2012), but it also increases the proficiency, creativity, and innovative behaviours of employees (Leroy et al., 2012; Slåtten \& Mehmetoglu, 2011; Slåtten et al., 2011) and organizational performance (Kim \& Brymer, 2011) as well. However, meta-analytic studies by Wang et al. (2018) and Koh et al. (2019) discuss the influence of TFL and TSL on employee outcomes.

Transformational leaders emphasize behaviours that encourage their followers/subordinates to execute beyond expectations (Avolio et al., 2004; Walumbwa et al., 2010) and increase the efficiency level of leaders (Tracey \& Hinkin, 1996). Transformational leaders have strong connections with ideas generation, crafting novel behaviour, and increasing the firm's innovative performance (Jiang \& Chen, 2018; Naguib \& Naem, 2018) through transitional constructs, i.e., organizational learning (García-Morales et al., 2012), empowerment (Jung et al., 2003), and culture (Steele et al., 2018). Scholars are captivated that leadership styles with intermediate constructs positively influence firm innovation (Rehman et al., 2019). Moreover, transformational leaders become helpful in enhancing trust and individual identification levels, which further promotes an innovative atmosphere in the workplace (Xie et al., 2018).

In contrast, transactional leaders clarify their followers' opportunities, anticipations, and rewards to accomplish organizational objectives (Chang et al., 2015; Rangus \& Černe, 2019). Additionally, transactional leaders rely on accomplishing tasks in exchange for appropriate and timely incentives (Xie et al., 2018). Past literature validates and takes a fractional attitude in probing TFL and TSL styles, converging on only one leadership style or interactions concerning TFL or TSL linking to situational and organizational physiognomies (Kark et al., 2018). It stretches the impression that operation and field managers frequently practice leadership styles to diversify and lead their employees (Qian et al., 2019). Numerous researchers examined TFL and TSL styles to facilitate innovative behaviours at individual and organizational levels (Jiang \& Chen, 2018; Kark et al., 2018; Nguyen et al., 2017; Steele et al., 2018).

Cohen and Levinthal (1990) argued that absorptive capacity (AC) is "the ability of firms to recognize the value of new, external information, assimilate it, and apply it to commercial ends" (p. 128). Moreover, Zahra 
and George (2002) intellectualized AC as an energetic capability intended by a set of routine organizational developments to differentiate into potential absorptive capacity (PAC) and realized absorptive capacity (RAC), as PAC is concerned with obtaining and clarification of exogenic knowledge and RAC concerned with transformation and application of knowledge. Earlier studies reveal that PAC produces several positive outcomes, i.e., enhancement in performance and reduction in cost, especially during the process of research and development by reducing the development cycles of new products (Caloghirou et al., 2004; Jones et al., 2001; Sisodiya et al., 2013). c (Araujo et al., 2003; Cegarra-Navarro et al., 2014; Cohen \& Levinthal, 1990). Recent studies demonstrate the positive affiliation between AC and innovation performance (Darwish et al., 2018; Xie et al., 2018).

Based on the theoretical foundation of diffusion of innovation theory (Rogers, 2003) and path-goal theory of leadership (House, 1996), the present study investigates the direct influence of leadership styles (TFL and TSL) on firms' innovative performance. Additionally, we examined the intervening influence of absorptive capacity (potential and realized) between the relationship of leadership (TFL and TSL) and firms' innovative performance. Secondly, the present study overcomes the gaps suggested by earlier researchers; there is a need to explore the effect of TFL and TSL, on the innovation process of products (Al-Husseini et al., 2019; Sheehan et al., 2020), with mediating mechanisms (Sheehan et al., 2020). This study added contributions within the context of a developing economy such as Pakistan. The present study contributes to the innovation arena by investigating the charm of leadership styles (TFL and TSL) through AC's (PAC and RAC) mediating effect, which opens new research curiosity linking AC, leadership styles, and firm innovation by explicating a comprehensive appraisal of the presented literature multidisciplinary parameters about firm's innovation. Moreover, the current study also contributes to the literature on leadership and $\mathrm{OB}$ by explaining the lends of diffusion of innovative theory and pathgoal theory of leadership.

\section{Theoretical foundation}

The research model of the present study is based on the notations of diffusion of innovation theory (Rogers, 2003) and path-goal theory of leadership (House, 1996) through which leadership styles (TFL and TSL), absorptive capacity (PAC and RAC), and firms' innovation are linking to shape the novel ideas and practices. The diffusion of innovation theory by Rogers (2003) discusses the communication process. The diffusion is 
concerned with process channels through which innovation is communicated at the workplace through team members; on the other side, innovation is concerned with an individual's novel, new and unique idea (Carreiro \& Oliveira, 2019; Zhou et al., 2019). Diffusion of innovation theory contributed in several diverse areas, i.e., marketing, innovation, and public health (Raven \& Walrave, 2020; Rogers, 2004), to facilitate leadership to realize the appropriate procedures for crafting novel ideas smoothly. Based on this notion, we argue that absorptive capacity in the presence of positive leadership enhances the innovation level of firms, as potential and realized absorptive capacity enables firms to generate new products and services through the interpretation of new and current knowledge. Path goal theory of leadership (House, 1996) discusses the leading behaviours of leaders through which they facilitate, guide, and help their subordinates/followers to achieve goals. Path goal theory (House, 1996) further explains that leaders' necessary support and direction enable their followers/subordinates to achieve organizational and individual goals. Leaders motivate their subordinates/followers and enhance commitment, satisfaction, and performance (Cho et al., 2019; House, 1996). We argue that leadership behaviour (TFL and TSL) increases absorptive capacity (PAC and RAC), further enhancing firms' innovation in producing new products and services at a lower cost.

Consequently, encompassing Rogers's conceptual work, we argue that leadership style needs diffusion and innovation gadgets to harvest new ideas specifically within the context when firms belong to a developing economy and are enthusiastic to upsurge competitiveness in the present market. Thus, extending this augmentation specified by Rogers (2003), we argued that employees/followers primarily need to assume novelties offered in front of them through their leaders. Consequently, the leadership styles (TFL and TSL) indicate a phenomenal charisma to peruse innovative infrastructure. From the above extant literature, we proposed our conceptual model. 
Mushtaq, I., Chughtai, M. S., \& Lashari, F.
Leadership Styles and Firms' Innovation, Mediating Role of Absorptive Capacity: Empirical Evidence from Emerging Economy

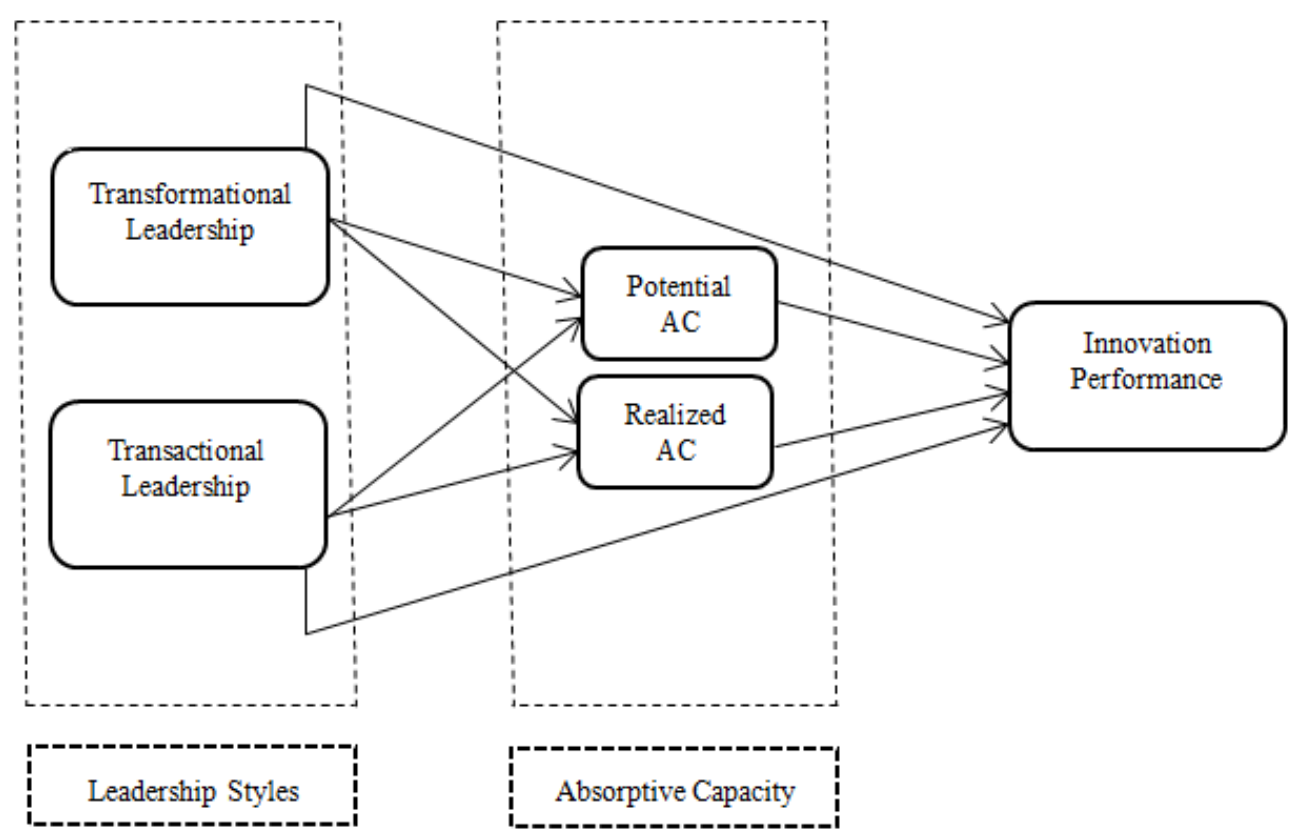

Figure1. Conceptual model

\section{Hypothesis development}

\subsection{Leadership styles and firms' innovation}

Every leadership style has different working inferences and influences on the productivity of individuals and firms and innovative activities that result in firms' innovation (Chen et al., 2019; Donate \& de Pablo, 2015). In any organization, the influence of leadership is crucial because it is an essential factor in the organization's productivity (Chan et al., 2018; Chan et al., 2016). Leaders are the powerful primary tool of the organization that provides freshness to their subordinates/followers, especially during organizational change through thriving (Chan et al., 2019).

Transformational leadership (TFL) is considered the favourite motivational leadership style that encourages followers/subordinates through better communication and provides a supportive intellectual environment (Chan et al., 2019). Transformation-oriented leaders inspire their followers/subordinates not only for creative and innovative thinking but also to create a positive environment for achieving organizational goals as a team (García-Morales et al., 2012). Numerous scholars stated that TFL is a vital capability of the firms, which not only promotes innovative 
thinking and the generation of creative and novel ideas but also influences individuals to the solution of complex and ill-defined problems at the workplace (Medeiros et al., 2017; Watts et al., 2020; Xie et al., 2018).

On the other hand, TSL deals with the transaction of exchange, as these leaders focus on extrinsic motivation and the self-interest of subordinates to achieve organizational goals (Bass et al., 2003). Transactional leaders manage their subordinates by giving them directions with responsibilities and rewards regarding accomplishing organizational goals and objectives (Avolio et al., 1999). These leaders achieve their organizational performance objective by launching strong expectations and goals plans through constructive feedback and an appropriate reward system (Avolio et al., 1999; Howell \& Hall-Merenda, 1999). This leadership style is formulated with the notion that effective leadership could encourage the activities of preferred followers and eradicate inappropriate behaviour patterns by providing or suppressing incentives and physically and psychologically punitive measures (Bass \& Bass, 2008). TSL is considered exchange leadership, which rewards employees for gaining and sharing new knowledge (Rawung et al., 2015), ultimately increasing the firms' innovation. Several studies asserted that TSL produces numerous positive outcomes, e.g., creativity (Herrmann \& Felfe, 2014), job and career satisfaction (Riaz \& Haider, 2010), employees engagement (Breevaart et al., 2014), and motivation (Wahyuni et al., 2014) as well. Based on the above discussion of literature, we propose that:

H1a: TFL is positively related to firms' innovation.

$\mathbf{H}_{1 \mathbf{b}}$ : TSL is positively related to firms' innovation.

\subsection{Leadership styles (TFL and TSL) and firms' innovation: the case of mediation of absorptive capacity (PAC and RAC)}

Innovation is the organizations concerned with generating new and novel ideas on how to apply new knowledge to produce new products and services and modify and improve existing ones (Leal-Rodríguez et al., 2014). Leadership styles project the firm's expectations and passion that enhance the firm's revolution by escalating the chances for their employees (Al-Husseini et al., 2019; Weintraub \& McKee, 2019; Zheng et al., 2016) and promote organizational success and values(Meyer \& Peng, 2016; Raisal et al., 2019). Leaders' actions display the leading power behind managerial innovation (Ferreras Mendez et al., 2018). TFL leaders are well-defined 
leaders, positively designate upcoming conditions for the organizations, and encourage employees' self-confidence by indulging their possible, converse, vibrant and manageable mission, and vision (Al-Husseini et al., 2019; Xenikou, 2017). Moreover, transformational leaders robust the visualization of innovation by enhancing the sharing of knowledge and information, increasing self-confidence for creativity and innovation (Al-Husseini et al., 2019; Avolio et al., 1999).

TSL leaders are usually jam-packed in their exchange tasks, expectations, and reward-based strategy, alienated into necessary units, i.e., contingent rewards and management-by-exception (Avolio et al., 1999; Bass et al., 2003). Leaders with a transactional style offer to motivate and enthusiast their followers/subordinates to attain specific organizational objectives by utilizing transactions/exchanges and grasping external knowledge sources through absorptive capacity (potential and realized) to facilitate innovation performance. Thus, we contend that potential and realized absorptive capacities demonstrate a compassionate atmosphere for transactional leaders to expedite innovation performance exclusively. The findings of the study conducted by Dorfman et al. (1997) demonstrate that Korean firms' employees were happier with transactional leaders to attain certain work-task within a particular time. Thus, extending certain logic, we posit that the TSL style can also be beneficial and facilitate the context of Pakistani firms when the object is about innovative performance within a particular period.

On the other side, the concern of $\mathrm{AC}$ is linked with the "acquisition, assimilation, transformation, and exploitation of external knowledge of firms" (Zahra \& George, 2002). This capability enables the firms to organize their internal resources according to the changing requirement of the markets so that a competitive advantage can be achieved ( $\mathrm{Wu}$ et al., 2019). Absorptive capacity holds two dimensions: potential AC, which is concerned with acquiring and assimilating knowledge, and realized AC discusses the transformation and exploitation of the knowledge (Zahra \& George, 2002). Large-volume organizations utilize PAC's benefits to enhance their performance because PAC provides the foundation of strategic thinking through the utilization of new knowledge that ultimately decreases financial and time costs (Chaudhary \& Batra, 2018; Jansen et al., 2005). In contrast, RAC helps organizations for the generation of new products and services and enables organizations to modify and improve their products and services according to the requirement of the market that, in return, gives them a competitive advantage (Ahmed et al., 2019; Ferreras Mendez et al., 2018). 
From this perspective, we argue that leadership style holds the quality of utilizing AC that increased the firm's innovation level. The organization's leadership style diverse the firm's internal knowledge and enables organizations to acquire and assimilate new external knowledge to enhance the creativity and innovation of the firm. ACs enable firms to enhance speed, frequency, and level of innovations (Cohen \& Levinthal, 1990), especially with supporting leadership styles, e.g., TFL and TSL. In certain high-rated situations, when firms acquire new knowledge and information via leadership, that stage, leadership becomes the ideal factor for firms to categorize, apprehend, and relate external knowledge to create better-quality innovation (Castillo \& Trinh, 2019; Medina et al., 2019).

Earlier studies evidenced that both dimensions of absorptive capacity (PAC and RAC) work as an intervening mechanism for enhancing innovative performance (Daspit et al., 2019; Raisal et al., 2019; Wu et al., 2019) with different predicting variables. Conversely, the study by Ahmad et al. (2019) evidenced that PAC does not hold any intervening mechanism. However, RAC indirectly influences the relationship between intellectual capital and business performance. In the developing economy context (e.g., Pakistan), it is crucially essential for the firms, either from the service or manufacturing sector, to adopt the practices of ACs (potential and realized) to utilize internal and external knowledge. These practices increase creativity and innovation and enhance the employees' capabilities with the support of efficient leadership (e.g., TFL and TSL). On the above literature deliberations basis, we propose our hypothesis: innovation.

$\mathbf{H}_{2 \mathbf{a}}$ : PAC mediates the relationship between TFL and firms'

$\mathbf{H}_{\mathbf{2}}$ : RAC mediates the relationship between TFL and firms' innovation.

H3a: PAC mediates the relationship between TSL and firms' innovation.

H3b: RAC mediates the relationship between TSL and firms' innovation. 
Mushtaq, I., Chughtai, M. S., \& Lashari, F.
Leadership Styles and Firms' Innovation, Mediating

Role of Absorptive Capacity: Empirical Evidence from

\section{Research methods}

\subsection{Sampling and data collection}

We collected data from Pakistani manufacturing firms (food and tobacco) because leadership activities have grown awareness in Pakistan, as innovations and their commercialization become mandatory for a developing economy (especially for Pakistani firms) to cater to the progressively sophisticated, fast-growing market with technologically demanding customers. The targeted population for the current study was permanent employees working in manufacturing sector organizations (food and tobacco) through the self-administered data collection method. In this technique, participants somewhat provide their opinion about the questions regarding the specific phenomenon of the study. Sampling is an obligatory requirement for any survey (Etikan et al., 2016); a convenient (nonprobability) sampling technique was used in this study to collect data. Convenience sampling is beneficial for researchers as it is available to researchers by its accessibility (Etikan et al., 2016). Participants of this study were approached through the respective organizations' HR departments; before the data collection, participants were briefed about the study objectives and the confidentiality of the data. The 350 questionnaires were sent to the manufacturing sector employees using electronic Google Forms and manual distribution methods. Three hundred-one questionnaires were received, completed from all aspects, and considered valid for further analysis, so the response rate was $86 \%$.

\subsection{Measurement development}

All study variables were analyzed on a seven-point Likert scale starting from having $(1=$ strongly disagree, $2=$ disagree, $3=$ slightly disagree, $4=$ neither agree nor disagree, $5=$ slightly agree, $6=$ agree, $7=$ strongly agree).

\subsubsection{Independent variables}

The transformational leadership (TFL) scale was alienated into five sub-divisions: idealized influence, inspirational motivation, intellectual stimulation, individualized consideration, and risk acceptance. Each subdivision consists of three major questions. This scale was developed and used by (Avolio \& Bass, 1998; Bass, 1990; Bass \& Avolio, 2000; Bass et al., 2003), and the Cronbach Alpha value was 0.79. The transactional 
leadership (TSL) scale was divided into three sub-divisions: contingent reward, management-by-exception, and laissez-faire leadership. This scale was developed and used by (Avolio \& Bass, 1998; Bass, 1990; Bass \& Avolio, 2000; Bass et al., 2003), and the Cronbach Alpha value was 0.72.

\subsubsection{Mediating variables}

Measurement of potential absorptive capacity (PAC) was assessed through a 12-items scale, but we deleted one item from the range developed by (Jansen et al., 2005; Zahra \& George, 2002), and Cronbach Alpha value was 0.84 . Measurement of realized absorptive capacity (RAC) was assessed through a 08 -items scale adopted, which was developed by (Jansen et al., 2005; Zahra \& George, 2002), and the Cronbach Alpha value was 0.82.

\subsubsection{Dependent variable}

Measurement belonging to innovative performance was assessed through a 05-items scale developed by (Chen et al., 2013; Chen et al., 2015; Ritala et al., 2015); the Cronbach Alpha value was 0.77. Therefore, the cumulative Cronbach value of all instruments for this study shows a significant Cronbach value of 0.70 , which according to (Lisawadi et al., 2019; Nunnally \& Bernstein, 1994), accepting the reliability of the apparatus, this scale of cognitive style indicator is reliable in Pakistani firms' context.

\section{Data analysis}

After data collection, SPSS version 25.0 and AMOS version 24.0 analyzed the collected data. Different tests were conducted to rehearse the data at the initial state. Descriptive statistics, validity, and composite reliability tests were rehearsed. To test the research hypothesis, hierarchical regression analysis (for direct impact) and Hayes PROCESS-macro (for the test of intervening impact) (Hayes, 2015, 2018) statistical techniques were used in this study. As data for the present study were collected at one time and reported by the same participant for all variables, CMB (common method bias) may exist. Thus, we conducted a single-factor analysis test suggested by Harman (1967) test, and the results show that the single fixed factor explains $31.3 \%$ of the variables' covariance. It is less than $40 \%$, so $\mathrm{CMB}$ does not play a significant role in this model. 
Mushtaq, I., Chughtai, M. S., \& Lashari, F.
Leadership Styles and Firms' Innovation, Mediating

Role of Absorptive Capacity: Empirical Evidence from Emerging Economy

\subsection{Descriptive statistics}

Of 301 respondents, 169 were male respondents (56\%), and 132 were female respondents (44\%). Table 1 endorses the validity of the questions asked to the respondents to measure the talent variables. Generally, our variables' alpha ranges started from 0.71 to 0.84 , which is quite good as they are higher than Cronbach's alpha benchmark (i.e., 0.70). TFL has been determined and carries alpha 0.79 and 0.77 , which is on the upper side of the acceptable rate. Correspondingly, PAC and RAC come with the help of (12 and 8) questions, and alpha is 0.84 and 0.82 , which is an exceptionally high range and illustrates sound reliability. Five questions were asked for the innovation performance, and its alpha is 0.77 , proving the reliability of the measurement instruments used in this study.

Table 1 . Reliability and validity

\begin{tabular}{llll}
\hline Construct & (AVE) & (CR) & Cronbach`s alpha \\
\hline Transformational leadership (TFL) & & & \\
\hline Idealized influence & 0.70 & 0.87 & 0.79 \\
Inspirational motivation & 0.51 & 0.75 & 0.71 \\
Intellectual stimulation & 0.56 & 0.79 & 0.72 \\
Individualized consideration & 0.59 & 0.81 & 0.74 \\
Risk acceptance & 0.53 & 0.77 & 0.77 \\
Transactional leadership (TSL) & & & \\
Contingent reward & 0.58 & 0.80 & 0.72 \\
Management-by-exception & 0.58 & 0.81 & 0.73 \\
Laissez-faire leadership & 0.85 & 0.94 & 0.91 \\
Potential absorptive capacity (PAC) & & & \\
Potential absorptive capacity (PAC) & 0.51 & 0.92 & 0.84 \\
Realized absorptive capacity (RAC) & 0.51 & 0.89 & 0.82 \\
\hline Innovation performance (INP) & 0.52 & 0.84 & 0.77 \\
\hline
\end{tabular}

\subsection{Confirmatory factor analyses}

To analyze the discriminant validity, we conducted CFA (confirmatory factor analyses) using AMOS 24.0. As shown in Table 2, the hypothesized five-factor model (with TFL, TSL, PAC, RAC, and INP) achieved an acceptable fit $(\chi 2=632.03, \mathrm{df}=179, \chi 2 / \mathrm{df}=3.53$, RMSEA $=$ 0.08 , IFI $=0.88$, CFI $=0.88)$. Further, we also tested numerous nested models by combining high-relevant constructs and one-factor models. 
Results in Table 2 show that the hypothesized model fit indexes are significantly well than other models. Thus, it proved that TFL, TSL, PAC, RAC, and INP could be statistically discriminant.

Table 2. CFA

\begin{tabular}{|c|c|c|c|c|c|c|}
\hline Model & $\chi^{2}$ & $\mathrm{df}$ & $\chi^{2 / \mathrm{df}}$ & RMSEA & IFI & CFI \\
\hline 5-Factor model (hypothesized model) & 632.03 & 179 & 3.53 & 0.08 & 0.88 & 0.88 \\
\hline 4-Factor model (TFL and TSL merged) & 1310.45 & 183 & 7.16 & 0.14 & 0.69 & 0.68 \\
\hline 4-Factor model (PAC and RAC merged) & 1116.86 & 183 & 6.10 & 0.13 & 0.74 & 0.74 \\
\hline $\begin{array}{l}3 \text {-Factor model (TFL and TSL merged, } \\
\text { PAC and RAC merged), }\end{array}$ & 1319.88 & 186 & 7.09 & 0.14 & 0.68 & 0.68 \\
\hline $\begin{array}{l}\text { 1-Factor (all items load on a single } \\
\text { factor) }\end{array}$ & 1436.94 & 189 & 7.60 & 0.15 & 0.65 & 0.65 \\
\hline
\end{tabular}

$\mathrm{N}=301$, TFL; transformational leadership, TSL; transactional leadership, PAC; potential absorptive capacity, RAC; realized absorptive capacity, INP; innovative performance.

\subsection{Correlations}

Table 3 demonstrates the bivariate correlational values of all the variables. According to the values, all study variables (TFL, TSL, PAC, RAC, and INP) correlated at the significance level of 0.01 .

Table 3. Correlations

\begin{tabular}{llllllll}
\hline Variable & M & SD & TL & TSL & PAC & RAC & INP \\
\hline TFL & 3.97 & 0.4017 & & & & & \\
TSL & 3.48 & 0.6723 & $0.419^{* *}$ & & & \\
PAC & 5.72 & 0.7033 & $0.696^{* *}$ & $0.180^{* *}$ & & & \\
RAC & 5.73 & 0.6937 & $0.722^{* *}$ & $0.284^{* *}$ & $0.806^{* *}$ & & \\
INP & 5.74 & 0.7549 & $0.695^{* *}$ & $0.229^{* *}$ & $0.746^{* *}$ & $0.795^{* *}$ & \\
\hline
\end{tabular}

$\mathrm{N}=301$, TFL; transformational leadership, TSL; transactional leadership, PAC; potential absorptive capacity, RAC; realized absorptive capacity, INP; innovative performance.

\subsection{Hypotheses testing}

Table 4 represents the hierarchal regression results of leaderships (TFL and TSL), absorptive capacities (PAC and RAC), and firm innovative performance. Models 2 and 3 show the regression of innovation performance on TFL and TSL. As hypothesized, TFL $(\beta=0.69, \mathrm{p}<0.001)$ and TSL $(\beta=0.26, p<.001)$ are significantly and positively influencing innovation performance. So, $\mathrm{H}_{1 \mathrm{a}}$ and $\mathrm{H}_{1 \mathrm{~b}}$ are supported. $\mathrm{PAC}$ has a significant influence on INP $(\beta=0.54, p<0.001)$, while the coefficient of TFL $(\beta=58, p<0.001)$ decreased sharply compared to model 4 , which 
Mushtaq, I., Chughtai, M. S., \& Lashari, F.
Leadership Styles and Firms' Innovation, Mediating Role of Absorptive Capacity: Empirical Evidence from Emerging Economy

implies PAC partially mediated the relationship between TFL and INP (supporting $\mathrm{H}_{2 \mathrm{a}}$ ). Similarly, in model 5, RAC has a significant influence on INP $(\beta=0.65, p<0.001)$, while the coefficient of TFL $(\beta=46, p<0.001)$ decreased sharply compared to model 8 , which implies RAC partially mediated the relationship between TFL and INP (supporting $\mathrm{H}_{2 b}$ ). In model 6, PAC has a significant influence on INP $(\beta=0.76, p<0.001)$. In contrast, the coefficient of TSL $(\beta=0.08$, n.s.) is insignificant, which implies PAC fully mediated the relationship between TSL and INP (supporting $\mathrm{H}_{3 \mathrm{a}}$ ). Similarly, in model 7, RAC has a significant influence on INP $(\beta=0.84, p<$ $.001)$, while the coefficient of TSL $(\beta=0.08$, n.s.) is insignificant, which implies RAC fully mediated the relationship between TSL and INP (supporting $\mathrm{H}_{3 \mathrm{~b}}$ ).

Table 4. Regression

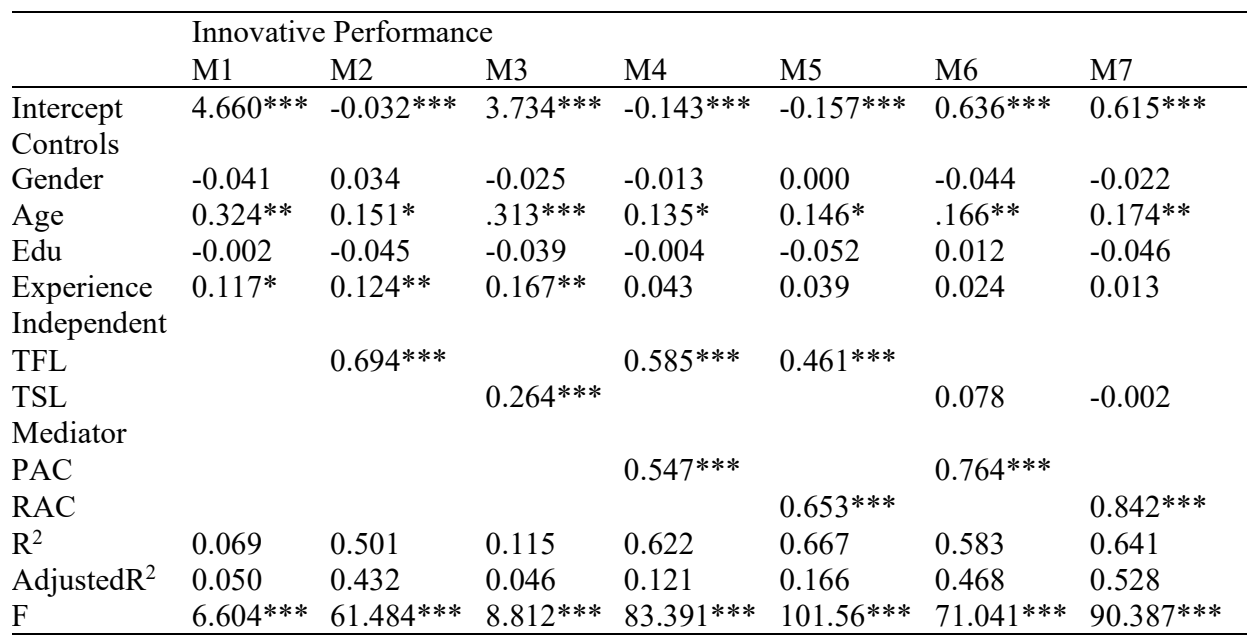

Note: $\mathrm{N}=301$, TFL; transformational leadership, TSL; transactional leadership, PAC; potential absorptive capacity, RAC; realized absorptive capacity, INP; innovative performance.

Further, we tested the indirect effects of TFL and TSL on INP via ACs. The procedure was conducted using PROCESS macro (Model 4) in SPSS, in which the sample was set to 5000, and finally produced $95 \%$ asymmetric confidence intervals. The indirect effect is significant if the $95 \%$ CI does not contain zero. Tables 5 present the bootstrapping results. For $\mathrm{H}_{2 \mathrm{a}}$ and $\mathrm{H}_{2 b}$, TFL's two specific indirect effects on INP through PAC and RAC are significant, respectively. In detail, the $95 \%$ CI via PAC ranged from. 121 to .639 , which did not contain 0 . The $95 \%$ CI via RAC ranged from .419 to .935, which also did not contain 0 . For $\mathrm{H}_{3 \mathrm{a}}$ and $\mathrm{H}_{3 \mathrm{~b}}$, the two specific indirect effects of TSL on INP through PAC (95\% CI range from .030 to .159) and 
RAC (95\% CI range from .101 to .276) are also significant, respectively. Therefore, the mediation effects of $\mathrm{H}_{2 a}, \mathrm{H}_{2 b}, \mathrm{H}_{3 a}$, and $\mathrm{H}_{3 b}$ all received support.

Table 5. Indirect effects

\begin{tabular}{lllll}
\hline The indirect effect of TFL on INP & Effect & Boot SE & $95 \%$ LLCI & $95 \%$ ULCI \\
\hline Total & 0.9689 & 0.1499 & 0.6850 & 0.2756 \\
Via PAC & 0.3339 & 0.1306 & 0.1215 & 0.6394 \\
Via RAC & 0.6349 & 0.1314 & 0.4197 & 0.9435 \\
(C1s) & -0.3010 & 0.2149 & -0.7137 & 0.1330 \\
\hline The indirect effect of TSL on INP & Effect & Boot SE & $95 \%$ LLCI & $95 \%$ ULCI \\
\hline Total & 0.2605 & 0.0571 & 0.1506 & 0.3810 \\
Via PAC & 0.0802 & 0.0324 & 0.0304 & 0.1592 \\
Via RAC & 0.1803 & 0.0431 & 0.1018 & 0.2768 \\
(C1s) & -0.1000 & 0.0504 & -0.2111 & -0.0088 \\
\hline
\end{tabular}

$\mathrm{N}=301$, TFL; transformational leadership, TSL; transactional leadership, PAC; potential absorptive capacity, RAC; realized absorptive capacity, INP; innovative performance.

\section{Discussions}

The primary purpose of the present study was to investigate the influence of leadership styles (TFL and TSL) on firms' innovation; we also examine the intervening influence of absorptive capacity (PAC ad RAC) between the relationship of leadership styles and firms' innovative performance, especially with the context of Pakistani manufacturing firms (food and tobacco). The diffusion of innovation theory (Rogers, 2003) and path-goal theory of leadership (House, 1996) provide the theoretical foundation for investigating this study's model. The first hypothesis of the present research predicted that both leadership styles (TFL and TSL) are positively related to firms' innovation. The present study's findings are also evident in accepting both portions of this hypothesis, $\mathrm{H}_{1 \mathrm{a}}$ and $\mathrm{H}_{1 \mathrm{~b}}$. The findings of the current study are also in line with the findings of earlier studies, which explained that leadership styles work as an antecedent of innovation of the firm (Jiang \& Chen, 2018; Kark et al., 2018; Nguyen et al., 2017; Steele et al., 2018). The second hypothesis of the current study predicted that both absorptive capacity (PAC and RAC) dimensions mediate the relationship between TFL and firms' innovation. The findings of the present study also prove both sections of hypotheses $\mathrm{H}_{2 \mathrm{a}}$ and $\mathrm{H}_{2 \mathrm{~b}}$.

Moreover, findings of the earlier studies also provide support to the results of this study by explaining that the PAC and RAC of the firm with 
Mushtaq, I., Chughtai, M. S., \& Lashari, F.
Leadership Styles and Firms' Innovation, Mediating Role of Absorptive Capacity: Empirical Evidence from

the presence of TFL increase the level of innovation of the firm (Castillo \& Trinh, 2019; Darwish et al., 2018; Kotabe et al., 2017; Naqshbandi \& Tabche, 2018; Wang et al., 2018) at the organizational and individual level. The third hypothesis of the present study predicted that both absorptive capacity (PAC and RAC) dimensions mediate the relationship between TSL and firms' innovation. The findings of the present study also prove both sections of hypotheses $\mathrm{H}_{3 \mathrm{a}}$ and $\mathrm{H}_{3 \mathrm{~b}}$. Moreover, findings of the earlier studies also provide support to the results of this study by explaining that the PAC and RAC of the firm with the presence of TSL increase the level of innovation of the firm (Darwish et al., 2018; Duan et al., 2020; Naqshbandi \& Tabche, 2018; Wang et al., 2020); as Naqshbandi et al. (2018) argued that leadership styles could be affected by the context of the observed leadership styles. This study confirmed that both TFL and TSL styles positively impact Pakistani firms' innovative performance through the intervening role of AC, sub-dimensions i-e, potential and realized. The results also support all the hypotheses, which show that effective leadership styles manipulate a firm's innovation through PAC and RAC.

\subsection{Theoretical and empirical implications}

This study found two effective leadership styles (TFL and TSL) positively related to absorptive capacity's sub-dimensions (potential and realized) and firms' innovation. Potential and realized AC adopted in firms with TFL and TSL styles encourage their employees to learn about the existing knowledge and escalate the new knowledge. Firms with improved and highly learned AC (potential, realized) enjoy higher individual and organizational innovation levels.

These findings have imperative theoretical implications. Previous studies on AC have less concern about which factors affect the AC inside the firms' settings; this study has proved that firms with effective leadership styles (TFL and TSL) commence new learning among employees for more constancy of AC (PAC and RAC), with the context of developing economy context. Previous studies generally observe the direct influence of the TFL style on innovation (Flatten et al., 2015; Nguyen et al., 2017). Second, previous studies have observed meaningful mediators in how the TFL and TSL leader affects a firm's innovation: culture, organizational citizenship behaviour, and employee commitment (Bian et al., 2019; Steele et al., 2018). Adopting diffusion of innovation theory (Rogers, 2003) and pathgoal theory of leadership (House, 1996), this study tries to clarify how and why novel ideas and technology can extend to address existing gaps in the literature concerning the mediating effect of potential and realized AC 
between effective leadership styles and a firm's innovation.

The findings of the present study also propose some managerial implications:

- Firms who desire to increase their absorptive capacity should concentrate on their manager's leadership styles; because leadership styles, e.g., TFL and TSL, help to escalate the new information and foster innovative ideas among the firm's employees.

- This study elucidates that it is helpful for managers to know about their outer relationships to develop absorptive capacity and focus on strategies to establish stability between the strength and width of leadership styles' requirements.

- The present study proposes that training managers about adopting the latest leadership styles increase managers' efficiency and learning level towards utilizing internal and external knowledge.

\subsection{Limitations and future suggestions}

This study carries several critical limitations; first, this study's findings are based on Pakistani firms (food and tobacco) and are probably limited in their generalizability to other developing country contexts. Future research should investigate multinational firms from other developing regions and compare the effective leadership styles investigated within innovation. Second, this study was intensified by the aspiration to expand a fine-grained understanding of the potential and realize AC's mediating function by testing alternative leadership styles encouraged in the future, such as authentic leadership, servant leadership, or creative leadership on a firm's innovation. Third, future research could also observe the moderating influence of knowledge characteristics such as acquisition, exploitation, and sharing knowledge through tacit and explicit sources and their impact on potential and realized AC with innovation. Finally, this research suggests that future studies must pay attention to cultural factors, e.g., (Sarooghi et al., 2015), to improve potential and realized AC towards innovations.

\subsection{Concluding remarks}

This study develops a theoretical model through the foundation of diffusion of innovation theory and path-goal theory of leadership to ascertain the influence of TFL and TSL leadership styles to strengthen the innovation process through ACs. We found that TSL and TFL leadership styles improved Pakistani firms' innovation level through potential and realized $\mathrm{AC}$ by recognizing the worth of new advanced knowledge - to 
Mushtaq, I., Chughtai, M. S., \& Lashari, F.
Leadership Styles and Firms' Innovation, Mediating Role of Absorptive Capacity: Empirical Evidence from Emerging Economy

absorb and utilize that knowledge to meet the worthwhile goals for achieving the competitive benefits.

\section{Declaration of conflicting interests}

The author(s) declared no potential conflicts of interest with respect to the research, authorship, and/or publication of this article.

\section{References}

Afsar, B., Masood, M., \& Umrani, W. A. (2019). The role of job crafting and knowledge sharing on the effect of transformational leadership on innovative work behavior. Personnel Review, 48(5), 1186-1208. https://doi.org/10.1108/PR-04-2018-0133

Afsar, B., \& Umrani, W. A. (2019). Transformational leadership and innovative work behavior: The role of motivation to learn, task complexity and innovation climate. European Journal of Innovation Management, EJIM-, 257, 12-2018. https://doi.org/10.1108/ejim-12-2018-0257

Ahmed, S. S., Guozhu, J., Mubarik, S., Khan, M., \& Khan, E. (2019). Intellectual capital and business performance: the role of dimensions of absorptive capacity. Journal of Intellectual Capital, 21(1), 23-39. https://doi.org/10.1108/jic-11-2018-0199

Al-Husseini, S., El Beltagi, I., \& Moizer, J. (2019). Transformational leadership and innovation: the mediating role of knowledge sharing amongst higher education faculty. International Journal of Leadership in Education, 1-24. https://doi.org/10.1080/13603124.2019.1588381

Araujo, L., Dubois, A., \& Gadde, L. E. (2003). The multiple boundaries of the firm. Journal of Management Studies, 40(5), 1255-1277. https://doi.org/10.1111/14676486.00379

Avolio, B. J., \& Bass, B. M. (1998). You can drag a horse to water but you can't make it drink unless it is thirsty. Journal of Leadership Studies, 5(1), 4-17. https://doi.org/10.1177/107179199800500102

Avolio, B. J., Bass, B. M., \& Jung, D. I. (1999). Re-examining the components of transformational and transactional leadership using the Multifactor Leadership. Journal of Occupational and Organizational Psychology, 72, 4. https://doi.org/10.1348/096317999166789

Bass, B. M. (1990). From transactional to transformational leadership: Learning to share the vision. Organizational Dynamics, 18(3), 19-31. https://doi.org/10.1016/00902616(90)90061-S

Bass, B. M., \& Avolio, B. J. (2000). MLQ: Multifactor leadership questionnaire. Mind Garden.

Bass, B. M., Avolio, B. J., Jung, D. I., \& Berson, Y. (2003). Predicting unit performance by assessing transformational and transactional leadership. Journal of Applied Psychology, 88(2), 207. https://doi.org/10.1037/0021-9010.88.2.207

Bass, B. M., \& Bass, R. (2008). The Bass Handbook of Leadership. Theory, Research and Managerial Applications. Free Press.

Bian, X., Sun, Y., Zuo, Z., Xi, J., Xiao, Y., Wang, D., \& Xu, G. (2019). Transactional leadership and employee safety behavior: Impact of safety climate and 
psychological empowerment. Social Behavior and Personality: an international journal, 47(6), 1-9. https://doi.org/10.2224/sbp.7295

Breevaart, K., Bakker, A., Hetland, J., Demerouti, E., Olsen, O. K., \& Espevik, R. (2014). Daily transactional and transformational leadership and daily employee engagement. Journal of Occupational and Organizational Psychology, 87(1), 138157. https://doi.org/10.1111/joop.12041

Caloghirou, Y., Kastelli, I., \& Tsakanikas, A. (2004). Internal capabilities and external knowledge sources: complements or substitutes for innovative performance? Technovation, 24(1), 29-39. https://doi.org/10.1016/s0166-4972(02)00051-2

Carreiro, H., \& Oliveira, T. (2019). Impact of transformational leadership on the diffusion of innovation in firms: Application to mobile cloud computing. Computers in Industry, 107, 104-113. https://doi.org/10.1016/j.compind.2019.02.006

Castillo, E. A., \& Trinh, M. P. (2019). Catalyzing capacity: absorptive, adaptive, and generative leadership. Journal of Organizational Change Management, 32(3), 356-376. https://doi.org/10.1108/jocm-04-2017-0100

Cegarra-Navarro, J.-G., Eldridge, S., \& Wensley, A. K. (2014). Counter-knowledge and realised absorptive capacity. European Management Journal, 32(2), 165-176. https://doi.org/10.1016/j.emj.2013.05.005

Chan, S. W., Ang, S. F., Andleeb, N., Ahmad, M., \& Zaman, I. (2019). The influence of transformational leadership on organization innovation in Malaysian manufacturing industry. International Journal of Supply Chain Management, 8(2), 971-976.

Chan, S. W., Omar, S. S., Ramlan, R., Ahmad, M. F., Zaman, I., \& Idrus, N. (2018). Emotional Intelligence and Transformational Leadership Among Managers in Manufacturing Companies. International Journal of Engineering \& Technology, 7(3.21), 1-4. https://doi.org/10.14419/ijet.v7i3.21.17083

Chan, S. W., Tiwari, S., Ramlan, R. B., \& Ahmad, M. (2016). The Relationship between Leadership Styles and Quality Management Practices in Malaysian Manufacturing Firms. International Conference on Industrial Engineering and Operations Management Kuala Lumpur, Malaysia,

Chang, J., Bai, X., \& Li, J. J. (2015). The influence of leadership on product and process innovations in China: The contingent role of knowledge acquisition capability. Industrial Marketing Management, 50, 18-29. https://doi.org/10.1016/j.indmarman.2015.04.014

Chaudhary, S., \& Batra, S. (2018). Absorptive capacity and small family firm performance: exploring the mediation processes. Journal of Knowledge Management, 22(6), 1201-1216. https://doi.org/10.1108/jkm-01-2017-0047

Chen, G., Farh, J.-L., Campbell-Bush, E. M., Wu, Z., \& Wu, X. (2013). Teams as innovative systems: Multilevel motivational antecedents of innovation in R\&D teams. Journal of Applied Psychology, 98(6), 1018. https://doi.org/10.1037/a0032663

Chen, J.-X., Sharma, P., Zhan, W., \& Liu, L. (2019). Demystifying the impact of CEO transformational leadership on firm performance: Interactive roles of exploratory innovation and environmental uncertainty. Journal of Business Research, 96, 8596. https://doi.org/10.1016/j.jbusres.2018.10.061

Chen, Y., Wang, Y., Nevo, S., Benitez-Amado, J., \& Kou, G. (2015). IT capabilities and product innovation performance: The roles of corporate entrepreneurship and 
Mushtaq, I., Chughtai, M. S., \& Lashari, F.
Leadership Styles and Firms' Innovation, Mediating Role of Absorptive Capacity: Empirical Evidence from Emerging Economy

competitive intensity. Information \& Management, 52(6), 643-657. https://doi.org/10.1016/j.im.2015.05.003

Cho, Y., Shin, M., Billing, T. K., \& Bhagat, R. S. (2019). Transformational leadership, transactional leadership, and affective organizational commitment: a closer look at their relationships in two distinct national contexts. Asian Business \& Management, 18(3), 187-210. https://doi.org/10.1057/s41291-019-00059-1

Cohen, W. M., \& Levinthal, D. A. (1990). Absorptive capacity: A new perspective on learning and innovation. Administrative Science Quarterly, 128-152. https://doi.org/10.2307/2393553

Darwish, T. K., Zeng, J., Rezaei Zadeh, M., \& Haak-Saheem, W. (2018). Organizational learning of absorptive capacity and innovation: Does leadership matter? European Management Review, 17(1), 83-100. https://doi.org/10.1111/emre.12320

Daspit, J. J., Long, R. G., \& Pearson, A. W. (2019). How familiness affects innovation outcomes via absorptive capacity: A dynamic capability perspective of the family firm. Journal of Family Business Strategy, 10(2), 133-143. https://doi.org/10.1016/j.jfbs.2018.11.003

Donate, M. J., \& de Pablo, J. D. S. (2015). The role of knowledge-oriented leadership in knowledge management practices and innovation. Journal of Business Research, 68(2), 360-370. https://doi.org/10.1016/j.jbusres.2014.06.022

Dorfman, P. W., Howell, J. P., Hibino, S., Lee, J. K., Tate, U., \& Bautista, A. (1997). Leadership in Western and Asian countries: Commonalities and differences in effective leadership processes across cultures. The Leadership Quarterly, 8(3), 233-274. https://doi.org/10.1016/s1048-9843(97)90003-5

Duan, Y., Wang, W., \& Zhou, W. (2020). The multiple mediation effect of absorptive capacity on the organizational slack and innovation performance of high-tech manufacturing firms: Evidence from Chinese firms. International Journal of Production Economics, 229, 107754. https://doi.org/10.1016/j.ijpe.2020.107754

Etikan, I., Musa, S. A., \& Alkassim, R. S. (2016). Comparison of convenience sampling and purposive sampling. American journal of theoretical and applied statistics, 5(1), 1-4. https://doi.org/10.11648/j.ajtas.20160501.11

Ferreras Mendez, J. L., Sanz Valle, R., \& Alegre, J. (2018). Transformational leadership and absorptive capacity: an analysis of the organisational catalysts for this relationship. Technology Analysis \& Strategic Management, 30(2), 211-226. https://doi.org/10.1080/09537325.2017.1299859

Flatten, T., Adams, D., \& Brettel, M. (2015). Fostering absorptive capacity through leadership: A cross-cultural analysis. Journal of World Business, 50(3), 519-534. https://doi.org/10.1016/j.jwb.2014.08.010

García-Morales, V. J., Jiménez-Barrionuevo, M. M., \& Gutiérrez-Gutiérrez, L. (2012). Transformational leadership influence on organizational performance through organizational learning and innovation. Journal of Business Research, 65(7), 1040-1050. https://doi.org/10.1016/j.jbusres.2011.03.005

Harman, D. (1967). A single factor test of common method variance. Journal of Psychology, 35(1967), 359-378.

Hayes, A. F. (2015). An Index and Test of Linear Moderated Mediation. Multivariate Behavioral Research, 50(1), 1-22. https://doi.org/10.1080/00273171.2014.962683

Hayes, A. F. (2018). Introduction to Mediation, Moderation, and Conditional Process Analysis (Second ed.). The Guilford Press.

Herrmann, D., \& Felfe, J. (2014). Effects of leadership style, creativity technique and 
personal initiative on employee creativity. British Journal of Management, 25(2), 209-227. https://doi.org/10.1111/j.1467-8551.2012.00849.x

House, R. J. (1996). Path-goal theory of leadership: Lessons, legacy, and a reformulated theory. The Leadership Quarterly, 7(3), 323-352. https://doi.org/10.1016/s10489843(96)90024-7

Howell, J. M., \& Hall-Merenda, K. E. (1999). The ties that bind: The impact of leadermember exchange, transformational and transactional leadership, and distance on predicting follower performance. Journal of Applied Psychology, 84(5), 680-694. https://doi.org/10.1037/0021-9010.84.5.680

Jansen, J. J., Van Den Bosch, F. A., \& Volberda, H. W. (2005). Managing potential and realized absorptive capacity: how do organizational antecedents matter? Academy of Management Journal, 48(6), 999-1015. https://doi.org/10.5465/amj.2005.19573106

Jiang, Y., \& Chen, C. C. (2018). Integrating knowledge activities for team innovation: Effects of transformational leadership. Journal of Management, 44(5), 1819-1847. https://doi.org/10.1177/0149206316628641

Jones, G. K., Lanctot Jr, A., \& Teegen, H. J. (2001). Determinants and performance impacts of external technology acquisition. Journal of Business Venturing, 16(3), 255-283. https://doi.org/10.1016/s0883-9026(99)00048-8

Jung, D. I., Chow, C., \& Wu, A. (2003). The role of transformational leadership in enhancing organizational innovation: Hypotheses and some preliminary findings. The Leadership Quarterly, 14, 4. 525-544. https://doi.org/10.1016/s10489843(03)00050-X

Kark, R., Van Dijk, D., \& Vashdi, D. R. (2018). Motivated or demotivated to be creative: The role of self-regulatory focus in transformational and transactional leadership processes. Applied Psychology, $\quad$ 67(1), 186-224. https://doi.org/10.1111/apps.12122

Kim, M.-S., \& Koo, D.-W. (2017). Linking LMX, engagement, innovative behavior, and job performance in hotel employees. International Journal of Contemporary Hospitality Management, 29(12), 3044-3062. https://doi.org/10.1108/ijchm-062016-0319

Kim, W. G., \& Brymer, R. A. (2011). The effects of ethical leadership on manager job satisfaction, commitment, behavioral outcomes, and firm performance. International Journal of Hospitality Management, 30(4), 1020-1026. https://doi.org/10.1016/j.ijhm.2011.03.008

Koh, D., Lee, K., \& Joshi, K. (2019). Transformational leadership and creativity: A metaanalytic review and identification of an integrated model. Journal of Organizational Behavior, 40(6), 625-650. https://doi.org/10.1002/job.2355

Kotabe, M., Jiang, C. X., \& Murray, J. Y. (2017). Examining the complementary effect of political networking capability with absorptive capacity on the innovative performance of emerging-market firms. Journal of Management, 43(4), 11311156. https://doi.org/10.1177/0149206314548226

Leal-Rodríguez, A. L., Roldán, J. L., Ariza-Montes, J. A., \& Leal-Millán, A. (2014). From potential absorptive capacity to innovation outcomes in project teams: The conditional mediating role of the realized absorptive capacity in a relational learning context. International Journal of Project Management, 32(6), 894-907. https://doi.org/10.1016/j.ijproman.2014.01.005 
Mushtaq, I., Chughtai, M. S., \& Lashari, F.
Leadership Styles and Firms' Innovation, Mediating Role of Absorptive Capacity: Empirical Evidence from Emerging Economy

Lebedev, S., Peng, M. W., Xie, E., \& Stevens, C. E. (2015). Mergers and acquisitions in and out of emerging economies. Journal of World Business, 50(4), 651-662. https://doi.org/10.1016/j.jwb.2014.09.003

Leroy, H., Palanski, M. E., \& Simons, T. (2012). Authentic leadership and behavioral integrity as drivers of follower commitment and performance. Journal of Business Ethics, 107(3), 255-264. https://doi.org/10.1007/s10551-011-1036-1

Lisawadi, S., Ahmed, S. E., Reangsephet, O., \& Shah, M. K. A. (2019). Simultaneous estimation of Cronbach's alpha coefficients. Communications in Statistics-Theory and Methods, 48(13), 3236-3257. https://doi.org/10.1080/03610926.2018.1473882

Medeiros, K. E., Watts, L. L., \& Mumford, M. D. (2017). Thinking inside the box: Educating leaders to manage constraints. In Handbook of research on creative problem-solving skill development in higher education (pp. 25-50). IGI Global. https://doi.org/10.4018/978-1-5225-0643-0.ch002

Medina, M. N., Ramachandran, I., \& Daspit, J. J. (2019). Collaboration Or Clash? Mapping The Effects Of Top Management Team Conflict On Firm Absorptive Capacity. International Journal of Innovation Management, 23(03), 1-29. https://doi.org/10.1142/s1363919619500233

Meyer, K. E., \& Peng, M. W. (2016). Theoretical foundations of emerging economy business research. Journal of International Business Studies, 47(1), 3-22.

Naguib, H. M., \& Naem, A. (2018). The impact of transformational leadership on the organizational innovation. The International Journal of Social Sciences and Humanities Invention, 5(1), 4337-4343. https://doi.org/10.18535/ijsshi/v5i1.15

Naqshbandi, M. M., \& Tabche, I. (2018). The interplay of leadership, absorptive capacity, and organizational learning culture in open innovation: Testing a moderated mediation model. Technological Forecasting and Social Change, 133, 156-167. https://doi.org/10.1016/j.techfore.2018.03.017

Nguyen, T. T., Mia, L., Winata, L., \& Chong, V. K. (2017). Effect of transformationalleadership style and management control system on managerial performance. Journal of Business Research, 70, 202-213. https://doi.org/10.1016/j.jbusres.2016.08.018

Nunnally, J. C., \& Bernstein, I. H. (1994). Psychometric theory (3rd ed ed.). McGraw-Hill.

Ohiorhenuan, J. F. (2019). Leadership and Development in Africa. In African Economic Development (Nnadozie, E. and Jerome, A. ed., pp. 315-330). Emerald Publishing Limited. https://doi.org/10.1108/978-1-78743-783-820192016

Padmanathan, K., Govindarajan, U., Ramachandaramurthy, V. K., \& Jeevarathinam, B. (2018). Integrating solar photovoltaic energy conversion systems into industrial and commercial electrical energy utilization-A survey. Journal of Industrial Information Integration, 10, 39-54. https://doi.org/10.1016/j.jii.2018.01.003

Qian, X., Fu, Y., Xiang, T., Jiang, Y.-G., \& Xue, X. (2019). Leader-based multi-scale attention deep architecture for person re-identification. IEEE transactions on pattern analysis and machine intelligence, 42(2), 371-385. https://doi.org/10.1109/tpami.2019.2928294

Raisal, I., Tarofder, A. K., \& Haleem, A. (2019). Interplay of Knowledge Creation Capability and Organizational Forgetting on Absorptive Capacity and Innovation Performance among SMEs: A Symmetrical Approaches. Asian Journal of Economics, Business and Accounting, 1-12. https://doi.org/10.9734/ajeba/2019/v11i430135

Rangus, K., \& Černe, M. (2019). The impact of leadership influence tactics and employee 
openness toward others on innovation performance. R\&D Management, 49(2), 168-179. https://doi.org/10.1111/radm.12298

Raven, R., \& Walrave, B. (2020). Overcoming transformational failures through policy mixes in the dynamics of technological innovation systems. Technological Forecasting and Social Change, 153, 119297. https://doi.org/10.1016/j.techfore.2018.05.008

Rawung, F. H., Wuryaningrat, N. F., \& Elvinita, L. E. (2015). The influence of transformational and transactional leadership on knowledge sharing: An empirical study on small and medium businesses in Indonesia. Asian Academy of Management Journal, 20(1), 123-145.

Rehman, S. U., Bhatti, A., \& Chaudhry, N. I. (2019). Mediating effect of innovative culture and organizational learning between leadership styles at third-order and organizational performance in Malaysian SMEs. Journal of Global Entrepreneurship Research, 9(1), 1-24. https://doi.org/10.1186/s40497-019-01591

Riaz, A., \& Haider, M. H. (2010). Role of transformational and transactional leadership on job satisfaction and career satisfaction. Business and Economic Horizons, 1(1), 2938. https://doi.org/10.15208/beh.2010.05

Ritala, P., Olander, H., Michailova, S., \& Husted, K. (2015). Knowledge sharing, knowledge leaking and relative innovation performance: An empirical study. Technovation, 35, 22-31. https://doi.org/10.1016/j.technovation.2014.07.011

Rogers, E. M. (2003). Diffusion of Innovations (5th ed.). Free Press.

Rogers, E. M. (2004). A prospective and retrospective look at the diffusion model. Journal of health communication, $9(\mathrm{~S} 1), 13-19$.

Rothfelder, K., Ottenbacher, M. C., \& Harrington, R. J. (2012). The impact of transformational, transactional and non-leadership styles on employee job satisfaction in the German hospitality industry. Tourism and Hospitality Research, 12(4), 201-214. https://doi.org/10.1177/1467358413493636

Saleem, M. A., Bhutta, Z. M., Nauman, M., \& Zahra, S. (2019). Enhancing performance and commitment through leadership and empowerment: An emerging economy perspective. International Journal of Bank Marketing, 37(1), 303-322. https://doi.org/10.1108/ijbm-02-2018-0037

Sarooghi, H., Libaers, D., \& Burkemper, A. (2015). Examining the relationship between creativity and innovation: A meta-analysis of organizational, cultural, and environmental factors. Journal of Business Venturing, 30(5), 714-731. https://doi.org/10.1016/j.jbusvent.2014.12.003

Schuckert, M., Kim, T. T., Paek, S., \& Lee, G. (2018). Motivate to innovate. International Journal of Contemporary Hospitality Management, 30(2), 776-796. https://doi.org/10.1108/ijchm-05-2016-0282

Sheehan, M., Garavan, T. N., \& Morley, M. J. (2020). Transformational leadership and work unit innovation: A dyadic two-wave investigation. Journal of Business Research, 109, 399-412. https://doi.org/10.1016/j.jbusres.2019.10.072

Sisodiya, S. R., Johnson, J. L., \& Grégoire, Y. (2013). Inbound open innovation for enhanced performance: Enablers and opportunities. Industrial Marketing Management, 42(5), 836-849. https://doi.org/10.1016/j.indmarman.2013.02.018

Slåtten, T., \& Mehmetoglu, M. (2011). What are the drivers for innovative behavior in frontline jobs? A study of the hospitality industry in Norway. Journal of Human 
Mushtaq, I., Chughtai, M. S., \& Lashari, F.
Leadership Styles and Firms' Innovation, Mediating Role of Absorptive Capacity: Empirical Evidence from Emerging Economy

Resources in Hospitality \& Tourism, 10(3), 254-272. https://doi.org/10.1080/15332845.2011.555732

Slåtten, T., Svensson, G., \& Sværi, S. (2011). Empowering leadership and the influence of a humorous work climate on service employees' creativity and innovative behaviour in frontline service jobs. International Journal of Quality and Service Sciences, 3(3), 267-284. https://doi.org/10.1108/17566691111182834

Steele, L. M., Watts, L. L., \& Den Hartog, D. N. (2018). Transformational leadership and innovation across cultures: A meta-analysis. Poster presented at the 33rd annual conference of the Society for Industrial and Organizational Psychology, Chicago, IL.

Tourish, D. (2014). Leadership, more or less? A processual, communication perspective on the role of agency in leadership theory. Leadership, 10(1), 79-98. https://doi.org/10.1177/1742715013509030

Tracey, J. B., \& Hinkin, T. R. (1996). How transformational leaders lead in the hospitality industry. International Journal of Hospitality Management, 15(2), 165-176. https://doi.org/10.1016/0278-4319(95)00059-3

Wahyuni, D. U., Christiananta, B., \& Eliyana, A. (2014). Influence of organizational commitment, transactional leadership, and servant leadership to the work motivation, work satisfaction and work performance of teachers at private senior high schools in Surabaya. Educational Research International, 3(2), 82-96.

Wang, L., Zhao, J. Z., \& Zhou, K. Z. (2018). How do incentives motivate absorptive capacity development? The mediating role of employee learning and relational contingencies. Journal of Business Research, 85, 226-237. https://doi.org/10.1016/j.jbusres.2018.01.010

Wang, Z., Ling, J., \& Chok, J. I. (2020). Relational embeddedness and disruptive innovations: The mediating role of absorptive capacity. Journal of Engineering and Technology Management, 101587. https://doi.org/10.1016/j.jengtecman.2020.101587

Watts, L. L., Steele, L. M., \& Den Hartog, D. N. (2020). Uncertainty avoidance moderates the relationship between transformational leadership and innovation: A metaanalysis. Journal of International Business Studies, 51(1), 138-145. https://doi.org/10.1057/s41267-019-00242-8

Weintraub, P., \& McKee, M. (2019). Leadership for innovation in healthcare: an exploration. International journal of health policy and management, 8(3), 138144.

Woods, S. A., Mustafa, M. J., Anderson, N., \& Sayer, B. (2018). Innovative work behavior and personality traits. Journal of Managerial Psychology, 33(1), 29-42. https://doi.org/10.1108/jmp-01-2017-0016

Wu, S., Ding, X., Liu, R., \& Gao, H. (2019). How does IT capability affect open innovation performance? The mediating effect of absorptive capacity. European Journal of Innovation Management, 24(1), 43-65. https://doi.org/10.1108/ejim-02-2019-0043

Xenikou, A. (2017). Transformational leadership, transactional contingent reward, and organizational identification: The mediating effect of perceived innovation and goal culture orientations. Frontiers in Psychology, 8, 1-13. https://doi.org/10.3389/fpsyg.2017.01754

Xie, Xue, W., Li, L., Wang, A., Chen, Y., Zheng, Q., Wang, Y., \& Li, X. (2018). Leadership style and innovation atmosphere in enterprises: An empirical study. Technological Forecasting and Social Change, 135, 257-265. 
https://doi.org/10.1016/j.techfore.2018.05.017

Zahra, S. A., \& George, G. (2002). Absorptive capacity: A review, reconceptualization, and extension. Academy of Management Review, 27(2), 185-203. https://doi.org/10.5465/amr.2002.6587995

Zheng, X., Yin, H., Liu, Y., \& Ke, Z. (2016). Effects of leadership practices on professional learning communities: The mediating role of trust in colleagues. Asia Pacific Education Review, 17(3), 521-532. https://doi.org/10.1007/s12564-016-9438-5

Zhou, E., Li, D., Madden, A., Chen, Y., Ding, Y., Kang, Q., \& Su, H. (2019). Modeling Adoption Behavior for Innovation Diffusion. In: Taylor N., Christian-Lamb C., Martin M., Nardi B. (eds) Information in Contemporary Society. iConference 2019. Lecture Notes in Computer Science, vol 11420. Springer, Cham. https://doi.org/10.1007/978-3-030-15742-5_33 